RAE-IC, Revista de la Asociación Española de Investigación de la Comunicación vol. 8, núm. 16 (2021), 121-141 ISSN 2341-2690

Recibido el 11 de agosto de 2021 DOI: https://doi.org/10.24137/raeic.8.16.7 Aceptado el 7 de octubre de 2021

\title{
Iconos femeninos actuales en las series de ficción de autoría femenina: estudio de caso de Bridgerton (Shondaland, 2020)
}

Current female icons in tv series created by women: case study of Bridgerton (Shondaland, 2020)

\author{
Cuenca Orellana, Nerea \\ Universidad Rey Juan Carlos (URJC) \\ nerea.cuenca@urjc.es
}

Martínez-Cano, Francisco-Julián

Universidad Miguel Hernández (UMH)

francisco.martinez.c@umh.es

Forma de citar este artículo:

Cuenca Orellana, N. y Martínez-Cano, F. J. (2021). Iconos femeninos actuales en las series de ficción de autoría femenina: estudio de caso de Bridgerton (Shondaland, 2020). RAEIC, Revista de la Asociación Española de Investigación de la Comunicación, 8(16), 121-141.

https://doi.org/10.24137/raeic.8.16.7

\section{Resumen:}

La representación de la mujer en las narrativas de ficción ha evolucionado desde la primera ola del Feminismo. Dado que las ficciones no han roto todavía con los estereotipos de género, el presente trabajo plantea un análisis de los tres personajes 
femeninos de la serie de Netflix Bridgerton (Shondaland, 2020), a través de una metodología cualitativa que aplica la tabla de análisis de personajes femeninos propuesta por Mar Chicharro (2018, p. 95). Esta herramienta se basa en variables clave en la construcción de personajes desde el punto de vista narrativo, pero además incluye cuestiones descriptivas que ayudan a abordar su evolución, como es el arco de transformación. El objetivo es constatar el cambio del criterio representacional de la mujer en la ficción audiovisual, que pasa de objeto de deseo masculino a sujeto activo orientado a satisfacer la demanda del público femenino al que va dirigida. Finalmente se presentan los resultados, entre los que destacan la evolución del personaje principal, desde la figura de princesa de cuento de hadas a heroína de la acción, así como la multirepresentación de la figura femenina a través de tres generaciones, estrategia empleada con el objetivo de cubrir el conjunto de la audiencia femenina.

Palabras clave: series de ficción, personajes femeninos, estudios de género, narrativa audiovisual, representación de la feminidad, arquetipos narrativos.

\section{Abstract:}

The representation of women in fictional narratives has evolved from the first wave of Feminism, and given that fictions have not yet broken with gender stereotypes, this paper proposes an analysis of the three female characters in the Netflix series Bridgerton (Shondaland, 2020), through a qualitative methodology that applies the table of analysis of female characters proposed by Mar Chicharro $(2018$, p. 95$)$. This tool is based on key variables in the construction of characters from the narrative point of view, but it also includes descriptive questions that help to address their evolution, the arc of transformation. The aim is to verify the change in the representational criterion of women in audiovisual fiction, which goes from being an object of male desire to an active subject oriented to satisfy the demand of the female audience to which it is addressed. Finally, the results are presented, including the evolution of the main character, from the figure of the fairy-tale princess to the heroine of the action, as well as the multi-representation of the female figure through three generations, a strategy employed with the aim of covering the female audience as a whole. 
Keywords: fiction series, female characters, gender studies, audiovisual narrative, representation of femininity, storytelling archetypes.

\section{INTRODUCCIÓN}

Los estudios de género que comenzaron en los años 60 y 70 con la Segunda Ola del Movimiento Feminista exigieron cambios en la representación audiovisual del icono femenino tradicional. El objetivo de estos estudios fue demostrar que era posible la participación activa en la narración del personaje femenino. En esta búsqueda de cambio de paradigma tuvo mucho que ver el trabajo de Laura Mulvey porque determinó que el icono femenino siempre aparecía como objeto de deseo del héroe protagonista de la acción narrativa. Mulvey quiso “dejar atrás el pasado sin rechazarlo, trascendiendo formas obsoletas o restrictivas, o atreviéndonos a romper con las expectativas placenteras normales" (1975, p. 4). La representación del icono femenino hasta entonces se situaba como objeto de deseo del varón protagonista, reforzando la desigualdad de género a través de las narrativas audiovisuales. En resumen, el varón daba vida a una masculinidad activa en la narración mientras que la mujer se presentaba como un ser pasivo (Parrondo Coppel y González Hortigüela, 2016, p. 63).

La ficción audiovisual hereda del conjunto de expresiones artísticas antecesoras, y en primera instancia de la literatura, formulando los paradigmas de la feminidad en el omnipresente medio que refleja y al mismo tiempo construye las realidades sociales (Marín y Solis, 2017, p. 42). En el contexto de los discursos artísticos la imagen femenina ha sido definida en clave a tres variables: "sumisión, pasividad y materialidad de su cuerpo" (Jiménez Gómez, 2020, p. 107). Antígona, Penélope, la Bella Durmiente, Elizabeth Benet en Orgullo y prejuicio (Austen, 1813), Fantine en Les Misérables (Hugo, 1862) o Escarlata O'Hara en Lo que el viento se llevó (Mitchell, 1936) dan vida a heroínas cuyo coraje se demuestra a través del sacrificio personal ante las adversidades del sistema patriarcal. Todas ellas eligieron el amor de pareja como símbolo de poder y medio para sobreponerse a la resignación, y así se trasladó de la literatura al cine. A 
finales del XX y principios del XXI el amor romántico de pareja deja de ser aquello que convierte en heroínas a los personajes femeninos. Encontramos, entonces, personajes femeninos como Arya Stark de Juego de Tronos (Martin, 1996) o Hermione Granger de la saga Harry Potter (Rowling, 1997), Offred de El cuento de la criada (Atwood, 1985) o Lisbeth Salander, de la saga Millenium (Larsson, 2005-2007 y Lagercrantz, 2015-2017) que renuevan la representación de la identidad femenina. "La cultura de masas crea modelos y uno de sus recursos es ofrecer situaciones y comportamientos a través de los que sugerir escenarios o protagonistas que la audiencia interiorice a través del proceso de inmersión" (Menéndez Menéndez, 2017, p. 417).

Las series de ficción contemporáneas proponen nuevos modelos femeninos, adquiridos de la corriente literaria de los últimos veinte años, que distan cada vez más de los estereotipos tradicionales. Sin embargo, cabe revisarlos porque continúan "reproduciendo la desigualdad en la representación de lo femenino y lo masculino" (Belmonte y Guillamón, 2008, p. 120).

Cada vez más, estos nuevos personajes femeninos se centran en cuestiones relacionadas con el "feminismo, madurez y dolor" (Gavilán, Martínez Navarro y Ayestarán, 2019, p. 375) sin que el amor romántico sea la pieza esencial de la madurez o heroicidad femenina. Los personajes femeninos adultos muestran gran capacidad de autodeterminación para afrontar sus problemáticas. La valentía y la fuerza son claves a la hora de enfrentarse a las convenciones a las que históricamente se han visto sometidas sea cual sea su edad. La relevancia de estos iconos femeninos y su forma de actuar reside en su poder socializador y transmisor de valores (Menéndez, Figueras-Máz y Núñez Angulo, 2017, p. 390).

Los roles de los personajes femeninos en la ficción contemporánea también evolucionan. La figura de la mujer dedicada a las labores domésticas y proveedora de cuidados trasciende a personajes que ocupan diferentes perfiles profesionales, no solo los tradicionales detectives y policías, sino roles como hackers (Lisbeth Salander en Millenium) o guerreras (Arya Stark en Juego de Tronos o Lagertha en Vikings). Estos nuevos roles promulgan la diversidad y equidad desde las ficciones de los formatos 
seriales que "transmiten al espectador interpretaciones y explicaciones de la estructura social, cómo se construyó en el pasado y cómo lo hace a día de hoy" (Cuenca Orellana y Martínez Pérez, 2020, p. 70).

Sin olvidar que varios estudios concluyen que la audiencia femenina es la que más series de ficción consume (Garitaonandia, Juaristi y Oleaga, 1999; Medrano y Cortés, 2008 y Menéndez Menéndez, Figeras-Máz, Núñez Angulo, 2017). Sin duda, estas producciones, en su intención de dirigirse hacia un público femenino dominante, tratan de abordar las cuestiones sobre los referentes femeninos y roles que ocupa en las ficciones actuales. Esto refleja el paulatino aumento de la presencia de mujeres detrás de las cámaras, que contribuye a la construcción de la figura femenina en estas producciones de una manera más acorde a la realidad de la mujer contemporánea y por ende mejor dirigida a su público objetivo. No olvidemos que, si las mujeres piensan diferente y viven su cultura de una manera distinta, los contenidos audiovisuales también tratan temas diferentes (Seger, 1996, p. 116).

La subordinación femenina en la industria audiovisual ha estado presente durante muchas décadas en puestos de responsabilidad y sello creativo (Higueras-Ruiz, 2019, p. 89). "La igualdad en el medio audiovisual dista mucho de haberse conseguido" (Martínez-Collado, Martínez y Navarrete Tudela, 2011, p. 10). Según CIMA -Asociación de mujeres cineastas y de medios audiovisuales-, la presencia de mujeres en los altos puestos de la industria española es escasa, con un 8,3\% de mujeres en los grupos directivos, de guionistas y producción frente al 91,7\% de hombres (2020, p. 111). Sin embargo, en el contexto norteamericano los datos muestran un incremento de la participación de las mujeres en los procesos creativos y de producción.

Según el informe Inclusion in Netflix Original U.S. Scripted Series \& Films, en relación a la producción de series entre 2017 y 2019, el 29,8\% de creadores son mujeres en la plataforma Netflix, siendo entre $2017-2018$ un $26,9 \%$ en la plataforma frente al $22 \%$ en la industria estadounidense. Del mismo modo, el porcentaje de mujeres productoras aumentó del 33,3\% de 2018 al 36,7\% en 2019, aunque la plataforma empleaba menos mujeres en los puestos de producción en 2018 que la industria estadounidense, en 2019 
este dato se equipara (Smith, Pieper, Choueiti, Yao, Case, Hernández y Moore, 2020, p. 10). Este aumento progresivo puede identificarse como el germen de la reformulación de la representación de los estereotipos de género y, en concreto de la figura de la mujer dentro de la pantalla, forjándose a través de las estrategias de adaptación a las expectativas de la industria empleadas por guionistas y creadoras para integrarse en la cultura televisiva, dominada por los hombres (Lauzen, Dozier, Horan, 2008, p. 206).

La autoría femenina de guiones para Netflix se situó en 2019 en un 41\% del total de producciones seriales, un $10 \%$ más aproximadamente respecto al 2018 . Respecto a la realización, del total de 1.666 directores de series que trabajan para la plataforma, el 27,7\% son mujeres (Smith, Pieper, Choueiti, Yao, Case, Hernández y Moore, 2020, p. 10). A este respecto, la serie Bridgerton (Shondaland, 2020) es un claro ejemplo, pues está basada en una novela escrita por una mujer, el guión de la serie lo firma un equipo formado por 5 mujeres y 1 hombre y la productora es Shonda Rhimes (Anatomía de Grey, 2005 y Scandal 2012). No podemos olvidar que el género define la forma en la que el creador ve el mundo y socializa, asimismo, elegir un protagonista femenino "condiciona la narración y la transforma en algo diferente" (Cuenca Orellana y Martínez Pérez, 2020, p. 114).

El giro en la representación de la figura femenina en las producciones audiovisuales presenta en la actualidad un impulso emergente en los formatos seriales. Esto se debe a su auge en el marco de las narrativas audiovisuales contemporáneas, potenciado por las plataformas de Vídeo Bajo Demanda, en las que también se observa una proliferación de contenidos dirigidos al público femenino, creados por mujeres (Gavilán, Martínez-Navarro y Ayestarán, 2019, p. 368). Esto último es clave en la reformulación de los personajes femeninos, pues “[...] el liderazgo de la producción por parte de una mujer showrunner tendrá consecuencias positivas en la caracterización de los personajes femeninos de dicha ficción" (Higueras-Ruiz, 2019, p. 99). El desarrollo de plataformas como HBO o Netflix han situado a la audiencia en el centro de los contenidos televisivos, en tanto decide qué consume y cómo, en función de una nueva lógica cultural (Schweidel y Moe, 2016; Jenner, 2017). 
El presente trabajo busca confirmar si "la irrupción de nuevos discursos ficcionales que comienzan a socavar las bases androcéntricas y heteronormativas de los discursos mediáticos" (Menéndez Menéndez y Zurián Hernández, 2014, p. 70) está instaurada en los personajes analizados o simplemente se modifica a nivel superficial. El objetivo principal de este trabajo se centra en determinar cómo se construye la feminidad en una serie de ficción creada, dirigida, destinada e interpretada por mujeres y basada en una obra literaria escrita por una mujer. El motivo de su elección es que ha sido desarrollada por la productora Shondaland, liderada por la showrunner Shonda Rhimes (EEUU, 1970-), nombrada una de las personas más influyentes de la industria audiovisual norteamericana por la revista Times en 2007. A día de hoy, Rhimes es considerada la showrunner más poderosa de Hollywood.

Como objeto de análisis de esta investigación nos centraremos en tres personajes clave de la serie Bridgerton (Shondaland, 2020). Daphne, Eloise y Lady Violet son miembros de la misma familia, pero plantean puntos de vista diferentes sobre cómo vivir y desarrollar la feminidad. Lady Violet es la madre de Daphne y Eloise, dos hermanas que representan modelos de feminidad diferentes. Partimos de la siguiente idea: "el protagonismo femenino en series comerciales para televisión es en sí mismo una forma de transgresión porque, además de paliar una invisibilización habitual en las industrias culturales, muchas de esas ficciones han logrado romper estereotipos de género" (Menéndez Menéndez y Zurián Hernández, 2014, p. 58). Y, por tanto, los objetivos específicos que se busca cubrir en este trabajo son los siguientes:

1. Descubrir cómo se representa a los personajes femeninos en las series de ficción: como objetos de deseo de un personaje masculino o como sujetos que se mueven a lo largo de la trama buscando sus propios objetivos narrativos.

2. Profundizar en cuáles son dichos objetivos narrativos y cómo se presentan los intereses personales femeninos: si están presentes las cuestiones femeninas tradicionales (matrimonio e hijos) o nos acercamos a las cuestiones femeninas más actuales: familia, trabajo, valor del sexo, romanticismo, maternidad, 
relación de poder con el varón, significado del cuerpo femenino y la importancia del grupo de pares (Chicharro, 2013, p. 14).

3. Comparar a los tres personajes femeninos con el propósito de revisar si existe una evolución interna (arco de transformación) individual en la representación de la feminidad.

\section{METODOLOGÍA}

Para llevar a cabo los objetivos planteados, se pretende profundizar en los personajes objeto de estudio y se utilizará la tabla de análisis de personajes femeninos propuesta por Mar Chicharro (2018, p. 95). Esta metodología se basa en variables clave en la construcción de personajes desde el punto de vista narrativo, es decir, cómo estos se mueven en la acción y se relacionan con otros personajes, ya sean de género femenino o masculino. Pero esta ficha de análisis también permite la descripción del personaje desde el enfoque de la representación de la feminidad. Concretando un poco más, a través del momento vital en el que se encuentran, el estado civil, la educación y profesión que desempeñan, habilidades emocionales, rol social y características principales, así como las relaciones sociales, familiares, sentimentales, amistosas o laborales podemos conocer cómo se representa la feminidad. Elementos como el arquetipo narrativo, objetivo dramático, conflictos que viven en la acción nos acercan a la representación de los personajes femeninos en las tramas, permitiendo que descubramos cómo evolucionan ya no como objetos de deseo, sino como sujetos.

Tabla 1. Análisis del personaje

\begin{tabular}{l}
\hline Etapa \\
\hline Estado civil \\
\hline Educación \\
\hline Profesión \\
\hline Arquetipo narrativo \\
\hline Características principales \\
\hline Habilidades emocionales \\
\hline Objetivo dramático
\end{tabular}




\begin{tabular}{l}
\hline Conflictos \\
\hline Relaciones con otros personajes \\
\hline Relaciones sentimentales \\
\hline Relaciones familiares \\
\hline Relaciones amistosas \\
\hline Relaciones laborales \\
\hline Rol de género \\
\hline Cambio de rol de género \\
\hline Espacios en los que aparece representada \\
\hline Justificación de su comportamiento
\end{tabular}

Fuente: Mar Chicharro (2018, p. 95)

\section{RESULTADOS}

Esta ficción gira en torno Daphne, la hija mayor de los Bridgerton, y su debut en el competitivo mercado matrimonial del Londres de la Regencia, en el que desea encontrar el amor verdadero y no un matrimonio de conveniencia. Cuando sus perspectivas se ven truncadas por su hermano mayor, comienza el juego entre Daphne y el Duque de Hastings, trama principal de la serie, en la que Lady Violet y Eloise, junto a la protagonista ejercen de personajes femeninos clave.

Sobre Lady Violet, con los datos recopilados a través de la tabla de análisis, podemos afirmar que es una mujer tradicional, feliz con la vida en pareja que ha tenido y la familia que ha construido. Frases como "a tu padre le pareció más ordenado" respecto a la elección de los nombres de sus ocho hijos (la inicial del nombre de cada uno corresponde a una letra del abecedario por orden alfabético: Anthony, Benedict, Colin, Daphne, Eloise, Francesca, Gregory y Hyacinth) dejan claro que ella estaba encantada con el hecho de complacer a su esposo.

Sus hijos la adoran y ella es cercana y amable con ellos, aunque no duda en sacar su carácter con Anthony, quien, al morir su padre, se ha convertido en el nuevo Lord Bridgerton. Lady Violet quiere que su hijo herede el cargo con responsabilidad y lo ejerza como tal. Así lo manifiesta desde el comienzo de la serie cuando el joven no está a

RAE-IC, Revista de la Asociación Española de Investigación de la Comunicación vol. 8, núm. 16 (2021), 121-141 
tiempo antes de partir a la presentación social de Daphne. En concreto, Lady Violet pregunta a su segundo hijo por el primogénito y cuando el joven responde que no sabe dónde está, le espeta: "Si tu hermano quiere ser aceptado como Lord Bridgerton, debe actuar como Lord Bridgerton" (00:02:54, 1x01), ante una nueva negativa, Lady Violet decide ir a la cita sin él. Con esta actitud muestra disciplina y capacidad de decisión, dejando claro que nos encontramos un personaje femenino fuerte y capaz de enfrentarse y resolver los conflictos que le surgen. Cuando llegan a palacio y se encuentra con su hijo mayor, le reprende delante de sus otros siete hijos. Precisamente, en ese momento (00:04:04, 1x01), vemos a Lady Violet en el centro de la imagen con todos ellos (Imagen 1).

Imagen 1. Lady Violet junto a sus hijos. (Capítulo 1, temporada 1: 00:04:04)

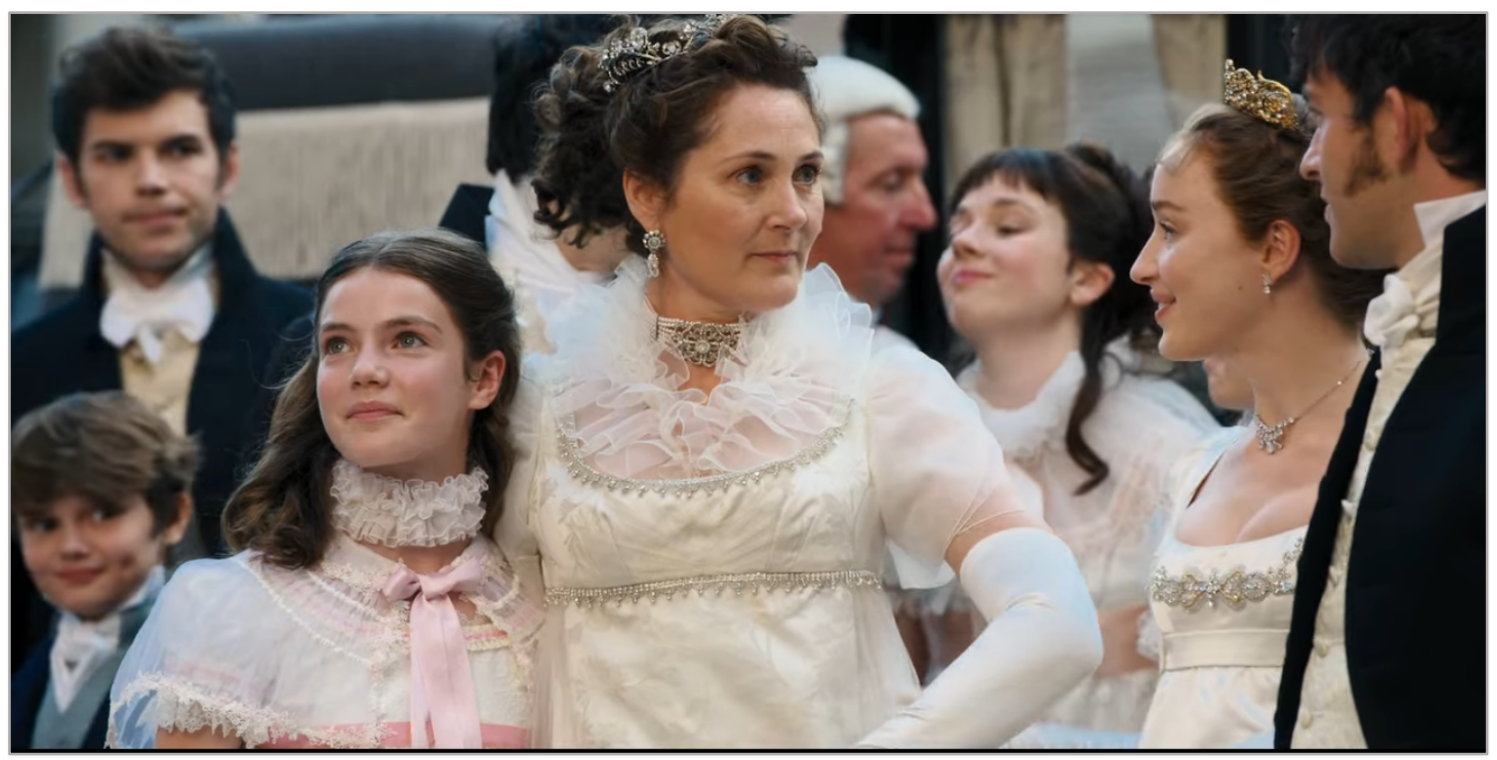

Fuente: Netflix; Shondaland 2020C

La imagen representa a una madre orgullosa de sus hijos, aunque molesta con el mayor al que mira directamente. A su izquierda aparecen quienes le están dando mucho trabajo como adolescentes y adultos, a la derecha de ella se encuentran los niños (tras Daphne está Francesca, quien se marcha a estudiar en el siguiente capítulo y no vuelve a aparecer hasta el capítulo final, 1x08) y detrás de Lady Violet queda Benedict, a quien la madre tapa (hecho que representa cuál será su actitud con él, puesto que le protege). Resalta la mirada de Daphne a su madre, por quien siente una profunda admiración. 
En el terreno social, Lady Violet es presentada como "viuda de Bridgerton" (00:05:45, 1x01). Esto nos deja claro que ella no tiene nombre a nivel social, sino que es conocida por haberse casado con Lord Bridgerton. Lady Violet siempre sabe cuál es su lugar, de hecho, cuando Daphne es presentada en sociedad, ella entra en segundo plano, detrás de su hija, pero cerca de ella.

La protagonista de la trama principal es Daphne. Según la tabla de análisis, nos encontramos con una joven guapa, rubia, tez clara, educada, familiar, soñadora, respetuosa, expresa sus ideas con claridad ante su familia. La joven, que debe tener unos dieciocho años, quiere casarse por amor, tal y como hicieron sus padres, tener un matrimonio feliz en el que poder tener hijos y darles lo que ella ha vivido. Esto lo defiende desde el primer capítulo, cuando declara "solo espero poder continuar con esa gran tradición" (00:09:10, 1x01). Comprobamos así que sus dos objetivos narrativos van unidos: casarse por amor y tener hijos.

Daphne representa el arquetipo narrativo de la princesa de los cuentos de hadas hasta el capítulo 4, a partir de entonces, se convierte en la heroína de la acción: está dispuesta a hacer todo lo posible por casarse por amor y honrar a su familia. Daphne se enamora de Simon Basset (duque de Hastings) progresivamente, dado que al principio considera que es un prepotente, arrogante y vividor, aunque según va descubriendo al joven, reconoce la sensibilidad y el respeto que él siempre le demuestra.

Cuando Simon le confiesa que no quiere casarse ni puede tener hijos, comienza el conflicto interno de la joven, que desea hacer lo correcto por su familia (honrarla ya que han descubierto que se besó con él en el jardín, algo prohibido en el siglo XIX) pero también quiere casarse por amor y a él no le ve convencido. Cuando los dos son vistos en el jardín y ella debe decidir, a pesar de que él le deja claro que, si se casan, no le dará hijos, ella, como buena heroína decide sacrificarse (00:57:55, 1x04). Daphne descubre que lo de no tener hijos no es debido a algo físico, sino que es porque él no quiere fallar a la palabra que dio a su padre en su lecho de muerte. Daphne hace todo lo posible para hacerle entender a él que su idea es producto de la venganza y eso les perjudica a ambos. De nuevo, la valentía y fuerza que demuestra el personaje femenino para 
enfrentarse a la situación es lo que la convierte en la heroína de su historia y con ello, deja ver su capacidad de decisión.

Daphne es una mujer tradicional al comienzo de la trama y se aprecia con el tema del matrimonio, ya entonces tiene claro que quiere casarse por amor y no por obligación, pero también manifiesta sus deseos de cumplir con los deberes femeninos impuestos por la sociedad. A lo largo de la acción se convierte en una mujer de finales del siglo XX defendiendo sus derechos de casarse con quien ella desee hasta convertirse en una mujer del siglo XXI una vez ya casada: ejerce como duquesa, mantiene sexo con su pareja por placer, sigue teniendo una buena relación con su familia y quiere conciliar todo esto con la maternidad. Es así como se presenta su cambio de rol (y de arquetipo narrativo), que viene marcado por el arco de transformación (evolución interior) que vive la joven a lo largo de la acción y los personajes que se encuentra en el camino. Esto nos subraya cómo "el cuento de hadas sobre encontrar el príncipe azul ya no es el único modelo que guía nuestras vidas. Parte de encontrar la verdad supone redefinir el mito" (Seger, 1996: 125) y es lo que se intenta en la serie objeto de análisis.

Los lugares en los que la joven aparece representada son su habitación y el salón de las visitas de su casa, el palacio y distintas fiestas a las que acude para conseguir esposo. También aparece representada en el exterior, pero, precisamente, las salidas al exterior de Daphne son siempre acompañada: bien por su madre o por su hermano mayor Anthony, excepto al jardín (espacio que simboliza el pecado en la religión cristiana) donde Simon la besa.

Daphne mantiene una buena relación con su madre, a quien obedece y copia, la admira profundamente y quiere seguir sus pasos como esposa y madre. La relación de Daphne con su hermano mayor, Anthony, es buena, pero ella manifiesta abiertamente sus deseos para que él no limite a los pretendientes. Es capaz de decirle lo que opina y reprender su actitud cuando en una conversación le dice "has asustado y alejado a todos los pretendientes" (00:32:10, 1x01). Daphne es la mayor de las chicas y quiere darles ejemplo. Con Eloise es condescendiente e intenta hacerla entrar en razón con el tema del matrimonio. Con el resto de sus hermanos interactúa menos, pero siempre de una 
forma cordial y cercana. Por tanto, la valentía, capacidad de decisión y fuerza para enfrentarse y arreglar cualquier situación sale a la luz no solo en su relación de pareja, sino en todas sus relaciones humanas.

En cuanto a Eloise, la joven también cuenta con una educación refinada, aunque no se interesa por la música, sino por la lectura, algo poco común en el siglo XIX pero que deja claro el interés de la muchacha por seguir aprendiendo. Su objetivo dramático se basa en que quiere acceder a los estudios superiores, pero sabe que esto no es posible y se queja de que sus hermanos varones sí hayan ido a la universidad, pero ella no pueda por ser mujer. La joven manifiesta abiertamente todas sus ideas, centradas, prioritariamente en no aceptar lo que la sociedad impone a las mujeres, sino en que ellas tengan voz y voto para decidir lo que deseen (Imagen 2). De los tres personajes, es el que menos aparece, aunque cuando lo hace, es para manifestar abiertamente que está del lado de su hermana y la respeta, aunque no comparta los deseos de Daphne en cuanto a casarse. Por tanto, también los actos y expresiones de Eloise se basan en la capacidad de decisión y fuerza para alcanzar su meta. En cualquier caso, ella no quiere casarse ni oír hablar del tema y le deja claro a su hermana mayor que ella no seguirá sus pasos (00:05:10, 1x05).

Imagen 2. Eloise dejando claro a Daphne que no seguirá sus pasos. (Capítulo 5, temporada 1: 00:05:10)

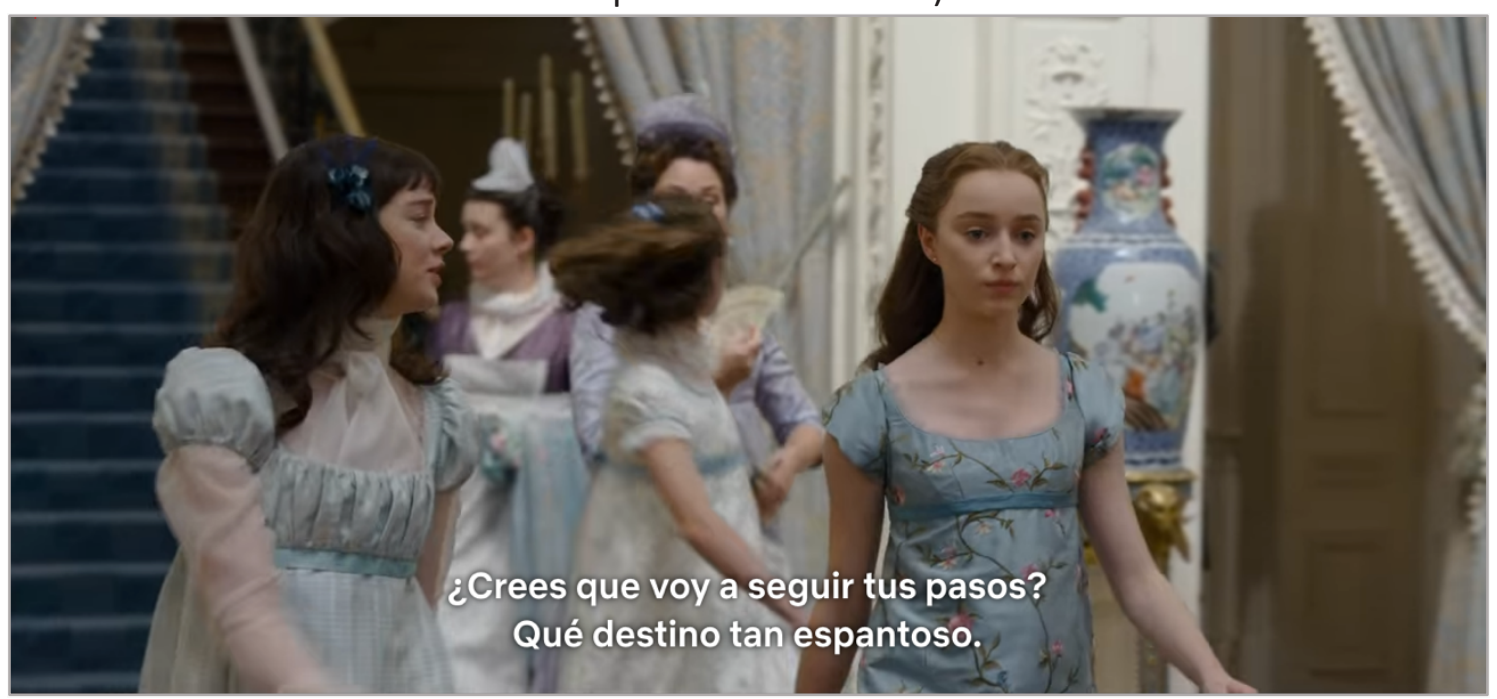

Fuente: Netflix; Shondaland 2020@ 


\section{DISCUSIÓN}

Las ficciones audiovisuales promueven arquetipos narrativos vinculados a los roles sociales, que son simplificados en estereotipos que se nos presentan como modelos de representación a lo largo de toda nuestra vida (Itmeizeh, 2017, p. 10). Christopher Vogler (analista de guiones y guionista estadounidense, 1949 -) defiende la existencia de una serie de arquetipos que aparecen en ese viaje del héroe y los define de la siguiente manera: un héroe, una sombra (villano), un heraldo, un mentor, un tramposo, un guardián del umbral y una figura cambiante (Vogler, 2002). Vladimir Propp, por su parte, consideró que en los cuentos de hadas se repetían siete arquetipos narrativos que servían como guía en el paso a la madurez de los pequeños. Propp clasificó a los personajes de las narraciones como villano, héroe, auxiliar, donante, falso héroe, mandatario y la princesa y el rey, estos dos últimos personajes aparecen en las obras literarias y los cuentos de hadas como una única unidad (Propp, 1998).

Según ambas categorizaciones, en el viaje de la heroína que Daphne realiza en la primera temporada de Bridgerton, la joven comienza siendo una princesa que necesita casarse, y en ausencia de su padre es su hermano mayor quien ejerce de figura paterna. La actitud de Anthony es negativa para Daphne porque nadie se acerca a pretenderla, por lo que la joven le pide que cambie de comportamiento. En dicha conversación le espeta: “¿Y qué pasa con mi deber? no tienes ni idea de lo que es ser una mujer, de lo que se siente cuando toda tu vida se reduce a un solo momento, he sido criada para esto, esto es lo que soy, no tengo otro valor, si no consigo encontrar un marido, no valdré nada" (00:32:15 del capítulo 1x01). Esta conversación marca un antes y un después en la joven que nos deja ver su carácter, su capacidad para decidir qué es lo mejor para ella y embarcarse en su propia aventura, no ya como princesa, sino como heroína de la acción.

La actitud de Daphne no es una novedad en la narración, así comenzó la liberación de los personajes femeninos a través de la acción: eligiendo ellas su propio destino y no aceptando el que la familia impusiera (Davis, 2006). Precisamente, ésta fue la evolución de princesas a heroínas en Disney a partir de 1991, que pasaron de limitarse a seguir su 
destino a pensar por sí mismas, tomar decisiones y crear su propia historia (Cuenca Orellana, 2019, p. 35).

Esto se ha trasladado a otras narraciones y Daphne lo representa claramente cuando, no se enfrenta a su padre, pero sí a su hermano mayor, quien ejerce de figura paterna ahora que Lord Bridgerton ha fallecido. Lo que no ha variado en el nivel de la construcción de la feminidad, Daphne da vida a la tradicional forma de representar el amor de pareja heredado de los cuentos de hadas: necesidad vital que empuja a los personajes a una vida mejor y más completa (Rodríguez y Cadete, 2018, p. 98). Esta forma de presentarnos a Daphne ya en el primer capítulo como princesa que se convierte en heroína al defender sus derechos y valores nos dejan claro que los arquetipos narrativos no varían, pero sí lo hacen las cualidades con las que se les representa en función de la época, el papel que desempeñan en la sociedad y el contexto sociocultural en el que se crean los personajes que componen la historia. Sin duda, esta cuestión es clave porque se construyen o mantienen nuevos roles de género que son simplificados en estereotipos y que los narradores nos transmiten en sus historias (Lauzen, Dozier y Horan, 2008, p. 201).

Vemos, además, otro hecho heroico de la joven cuando, tras enterarse de que la han visto a solas en el jardín con Simon, la noche que la besó, consigue parar el duelo entre Anthony y Simon para decidir casarse y sacrificar su maternidad, mostrando cómo todo hecho heroico pasa por servir y proteger. "Por encima de procedencias, culturas, ambientes y profesiones, ¿qué es un héroe? Ante todo, un protector y un servidor" (Sánchez-Escalonilla, 2002, p. 18). Y, en concreto, en el caso de Daphne, la joven desea servir a su familia y proteger el honor de todos sus miembros.

Unido a la evolución de Daphne y su comportamiento heroico, está la relación con su madre, quien, en la narración actúa como mentora de la joven. De hecho, como en otros contenidos audiovisuales de la segunda década del siglo XXI, "la madre se convierte en una pieza esencial del desarrollo y la evolución hacia la autonomía y heroicidad" (Cuenca Orellana, 2019, p. 328). La relación Lady Violet y Daphne (madre-hija) es positiva y constructiva. A esto hay que añadir la importancia de que aparezcan mujeres de 
distintas edades en los contenidos audiovisuales puesto que plasmar mujeres de distintas edades construyen nuevos conflictos, generan cambios en las historias y se crean personajes de una gran riqueza que logran romper estereotipos (Seger, 1996, p. 175). Lady Violet aparece al lado de su hija siempre, dándole apoyo, comprensión, escuchándola y apoyándola, le aconseja continuamente que piense por sí misma y conduzca su vida. Esta representación madre-hija es propia de las últimas décadas donde se busca un acercamiento. Éste es un punto clave en la evolución de la representación de la relación maestro-discípulo, tan presente en el viaje del héroe masculino, y que, en los viajes de las heroínas, ellas crecen y evolucionan junto a la figura materna y no alejándose de ellas.

Lady Violet es la mentora que un día fue heroína y, por tanto, ya ha pasado por todos los estadios por los que caminará la joven inexperta, por este motivo, Lady Violet considera esencial estar a su lado para guiarla. Las dos se respetan, conversan y comparten muchos puntos. Daphne quiere emular a su madre, pero, Lady Violet le aconseja que no siga sus pasos, que ella es libre para conseguir desarrollar su vida siendo feliz tal y como desee puesto que ella no quiere imponer nada. Esta construcción de la relación madre-hija forma parte del constructo social de modelos positivos y comportamientos correctos. No olvidemos que la ficción busca "ofrecer situaciones y comportamientos mediante los cuales sugiere escenarios o protagonistas con el fin de que sean interiorizados por la audiencia a través del proceso de inmersión" (Menéndez Menéndez y Zurián Hernández, 2014, p. 58).

Convertirse en madre es uno de los dos objetivos narrativos que Daphne persigue desde el primer capítulo, sin embargo, Simon le dice que no puede darle hijos. Aun así, desde la boda en adelante, los jóvenes practican sexo. En las series de ficción, "la sexualidad es dibujada, sobre todo, como un foco de placer" (Chicharro, 2013, p. 23). Precisamente, la sexualidad femenina por placer y no para tener descendencia se convierte en una de las novedades de las representaciones femeninas en los productos audiovisuales estrenados en las dos últimas décadas. Daphne y Simon disfrutan juntos del placer que les provoca mantener relaciones sexuales. Aun así, con los duques de Los Bridgerton 
volvemos a la representación tradicional del amor romántico y la sexualidad dentro del matrimonio. "En el futuro, los investigadores deberían considerar el sexo más allá de los dominios heteronormativos. Eso también incluye considerar que el sexo es, muchas veces, simplemente por placer y no involucra aspectos negativos" (Manning, 2021, p. 20). Bien es cierto que Daphne no es consciente de que ella no quedará embarazada porque su esposo no eyacula en su interior. La joven desconoce que el embarazo esté relacionado con el acto sexual hasta que le pregunta abiertamente a su doncella Rose, quien es la encargada de explicarle todo. Hasta aquí, se comprueba que las series se han desarrollado siguiendo el orden patriarcal, pero sin dejar de lado los cambios sociales que se están produciendo (Menéndez Menéndez y Zurián Hernández, 2014, p. 65).

\section{CONCLUSIONES}

Tras esta revisión y análisis de la serie Bridgerton, nos presenta discursos ficcionales tradicionales (búsqueda de esposo, matrimonio e hijos y cumplir con el deber) en los que la novedad se encuentra en la forma en la que los personajes femeninos se enfrentan a su destino. Por este motivo, podemos decir que la modificación es relevante, pero no total. A partir de aquí, se ha podido comprobar que los tres personajes femeninos son muy diferentes entre sí pero que las tres son activas en la narración y para ello, no esperan el amor, sino que eligen su propio destino, toman sus decisiones, se enfrentan ellas mismas a los problemas y los resuelven con seguridad y firmeza.

La serie Bridgerton construye a través de sus tres personajes femeninos principales una representación poliédrica de la mujer, en la que Lady Violet representa la feminidad del pasado, Daphne se sitúa en el presente (elegir esposo y tener hijos por sí misma, no por imposición o imitación) y Eloise formula la mujer del futuro inmediato, dando vida a la mujer que quiere algo diferente de lo que la sociedad le exige, contraponiéndose a las convenciones sociales impuestas. Esta estrategia atiende a la perfecta orquestación de la narrativa en función de los diferentes segmentos de público femenino al que va dirigida, incluyendo estos tres arquetipos en una misma ficción, pertenecientes a una misma familia, presenta de una manera eficaz la idea de poder que la mujer ejerce para 
evolucionar y elegir cuál es el icono que mejor representa la feminidad que cada espectadora quiere desarrollar en su día a día. Por lo tanto, el objetivo del diseño narrativo y la evolución de los personajes, pretende alcanzar a la totalidad de su audiencia redefiniendo y actualizando los roles y representaciones de sus personajes femeninos y su relación con los masculinos.

Cabe resaltar la innovación de esta ficción, de cómo plantea temáticas y conflictos actuales dentro de su espacio-tiempo ficcional, situado en el XIX, planteando en los personajes femeninos ciertas conductas que la mujer de esta época no podía contemplar. Este hecho, sin duda conecta a los personajes de esta producción a otras antecesoras, como es el caso de Mujercitas (Little Women, Gerwig, 2019; Armstrong, 1994; LeRoy, 1949), aunque no comparten el mismo contexto histórico, la construcción femenina de los personajes hereda de los arquetipos que se construyen tanto en los metrajes y en la novela en la que se basan: Little Women (Alcott, 1868), escrita por una autora femenina del XIX. Sin duda se observa una evolución en la construcción de la figura femenina, abordando cuestiones como el sexo como disfrute y no con el objetivo de reproducirse, por lo tanto, desde una perspectiva contemporánea.

En esta producción de Netflix, el leading role femenino se posiciona como principal frente al masculino. Este hecho responde al progresivo cambio de paradigma en las construcciones de los discursos femeninos y sus protagonistas, resultado en gran medida de la incorporación de la mujer en los procesos de creación y producción de las narrativas audiovisuales contemporáneas, con el fin de romper definitivamente el techo de cristal de las industrias culturales y en consecuencia de la audiovisual. Además, en la obra objeto de estudio el contexto ficcional explota inicialmente la construcción protagónica de la mujer desde la mirada tradicional, y aprovecha esta como vehículo evolutivo de la representación de los mismos personajes, en una suerte de innovación vestida de tradición. Bridgerton es un ejemplo clave en la evolución del paradigma de representación de la mujer en la ficción audiovisual, en el cambiante universo de los géneros esta producción los reformula a través del drama romántico, característico de los modelos convencionales femeninos en la ficción audiovisual. 
Del mismo modo, se identifica la necesidad de representar todas las feminidades posibles en contenidos audiovisuales, haciendo igual de válidas e importantes las elecciones que cualquiera de ellas tome por sí misma, aunque es la protagonista y heroína la que representa el icono femenino actual. Este hecho subraya la necesidad de iconos representativos de hoy en día que faciliten la socialización de los espectadores sean del género que sean y justifiquen la forma de actuar, la importancia de las cuestiones femeninas en el desarrollo humano individual y social de las mujeres.

\section{REFERENCIAS BIBLIOGRÁFICAS}

Belmonte-Arocha, J. y Guillamón-Carrasco, S. (2008). Co-educating the gaze against gender stereotypes in TV. [Co-educar la mirada contra los estereotipos de género en TV]. Comunicar, 31, 115-120. https://doi.org/10.3916/c31-2008-01-014

CIMA-Asociación de mujeres cineastas y de medios audiovisuales. (2020). Estereotipos, roles y relaciones de género en series de televisión de producción nacional: un análisis sociológico. Instituto de la Mujer y para la Igualdad de Oportunidades Ministerio de Igualdad. España.

Chicharro Merayo, M. (2018). Spanish History and Female Characters. Representations of Women in Spanish Historical Fiction. Convergencia UAEM, 77, 77-98.

Cuenca Orellana, N. (2019). La construcción del género en las películas de Pixar Animation studios entre 1995 y 2015: modelos de masculinidad, feminidad y relaciones entre personajes. Tesis doctoral. Universidad de Burgos: Burgos.

Cuenca Orellana, N. y Martínez Pérez, N. (2020). Igualdad de género y animación infantil en España: Myriam Ballesteros. Revista Internacional de Comunicación y Desarrollo, 3(12), 103-114.

Cuenca Orellana, N. y Martínez Pérez, N. (2020). Reescribiendo la feminidad en las series españolas: las nuevas heroínas en La Otra Mirada. Monográfico Narrativa, ética y estética de la serialidad televisiva, 2, 69-77. 
Davis, A. (2006). Good Girls and Wicked Witches. Women in Disney's Feature Animation. Bloomington, Estados Unidos: Indiana University Press.

Gavilán, D., Martínez-Navarro, G. y Ayestarán, R. (2019). Las mujeres en las series de ficción: el punto de vista de las mujeres, en Investigaciones feministas, 10(2), 367-384.

Higueras-Ruiz, M. J. (2019). Showrunners y personajes femeninos en las series de ficción de la industria televisiva norteamericana: Sharp Objects (Marti Noxon, HBO: 2018) y Killing Eve (Phoebe Waller-Bridge, BBC America: 2018-). Admira, 7, 85-106. http://dx.doi.org/10.12795/AdMIRA.2019.07.04

Jenner, M. (2017). Binge-watching: Video-on-demand, quality TV and mainstreaming fandom. International journal of cultural studies, 20(3), 304-320.

Jiménez Gómez, C. (2020). Sirenas caníbales y strippers en el cine: la feminidad monstruosa en The Lure (2015) de Agnieszka Smoczynska. Esferas Literarias, 3, 107-127. Lauzen, M., Dozier, D. y Horan, N. (2008). Constructing Gender Stereotypes Through Social Roles in Prime-Time Television, Journal of Broadcasting \& Electronic Media, 52(2), 200-214. https://doi.org/10.1080/08838150801991971

Manning, J. (2021). Comunicación sobre sexo: implicaciones para las relaciones, la salud, la cultura y la identidad. Una revisión. Profesional De La Información, 30(1). https://doi.org/10.3145/epi.2021.ene.14

Marín, V. y Solís, C. (2017). Los valores transmitidos por las mujeres de las películas Disney. Revista CS, (23), 37-55.

Martínez-Collado Martínez, A. y Navarrete Tudela, A. (2011). Mujeres e (industria) audiovisual hoy: involución, experimentación y nuevos modelos narrativos, en Barrios Vicente, I. M. (Coord.) Mujeres y la sociedad de la Información. Revista Teoría de la Educación: Educación y Cultura en la Sociedad de la Información, 12(2), 8-23.

Menéndez Menéndez, M. I. y Zurián Hernández, F. A. (2014). Mujeres y hombres en la ficción televisiva norteamericana hoy. Anagramas Rumbos y Sentidos de la Comunicación, 13(25), 55-71. 
Menéndez Menéndez, M. I. (2017). Mujeres y poder: Amazonas en el cine contemporáneo para adolescentes. Investigaciones Feministas 2(8), 415-428.

Menéndez Menéndez, M. I., Figueras-Máz, M. y Núñez Angulo, Bz. (2017). Consumo y percepción juvenil sobre la ficción seriada televisiva: influencia por sexo y edad. OBETS: Revista de Ciencias Sociales, 12(2), 369-394.

Mulvey, L. (1975). Placer visual y cine narrativo. Screen 16, 3, 6-18.

Parrondo Coppel, E., y González-Hortigüela, T. (2016). Releyendo a Laura Mulvey 40 años después. Historiografía y feminismo. Secuencias, (42), 53-72.

https://doi.org/10.15366/secuencias2016.42.003

Propp, V. (1998). Morfología del cuento. Madrid: Akal.

Rodríguez, J. y Cadete, T. (2018). La bella y la bestia. Todos somos contadores de cuentos. En M. Fanjul, Los cuentos infantiles y la transmisión de estereotipos: las creencias limitadoras (pp. 63-114). Madrid: AMEC.

Sánchez-Escalonilla, A. (2002). Guión de aventura. Tramas de forja heroica. Barcelona: Ariel.

Seger, L. (1996). When women call the shots: the developing power and influence of women in television and film. New York, Estados Unidos: Henry Holt and Company Inc.

Smith, S. L., Pieper, K., Choueiti, M., Yao, K., Case, A., Hernandez, K. y Moore, Z. (2021). Inclusion in Netflix Original US Scripted Series \& Films. INDICATOR, 46, 50-6.

Schweidel, D. A. y Moe, W. W. (2016). Binge watching and advertising. Journal of Marketing, 80(5), 1-19.

Vogler, C. (2002). El viaje del escritor. Las estructuras míticas para escritores, guionistas, dramaturgos y novelistas. Madrid, España: Ma Non Troppo. 